\title{
Pemetrexed-Induced Interstitial Pneumonitis: A Case Study and Literature Review
}

\author{
Michael J. Waters $^{\mathrm{a}, \mathrm{c}}$, Shawgi Sukumaran ${ }^{\mathrm{b}}$, Chris S. Karapetis ${ }^{\mathrm{b}}$
}

\begin{abstract}
Pemetrexed is a new-generation antifolate drug, now widely used in patients with non-small cell lung cancer (NSCLC). We report a case of pemetrexed-induced interstitial pneumonitis, and review the literature of eight previously reported cases. As pemetrexed is now a widely used chemotherapeutic agent, it is important to be aware of rare adverse events related to its administration.
\end{abstract}

Keywords: Chemotherapy; Interstitial pneumonitis; Pemetrexed; Lung toxicity; Non-small cell lung cancer; Treatment-related complication

\section{Introduction}

Pemetrexed is a new-generation antifolate drug. Intracellularly, pemetrexed and its polyglutamate derivatives potently inhibit multiple tetrahydrofolate-cofactor-requiring enzyme pathways [1]. It has hence been referred to as a "multitargeted" antifolate [2].

Pemetrexed is currently widely used in subsets of patients with non-small cell lung cancer (NSCLC): as first-line combination chemotherapy with cisplatin in patients with non-squamous pathology [3], as second-line monotherapy following initial treatment with platinum-based chemotherapy [4], and more recently as maintenance chemotherapy in non-progressing patients following platinum-based first-line chemotherapy [5]. Pemetrexed is also used as combination chemotherapy with cisplatin for malignant pleural mesothelioma [6]. The phase III clinical trials which led to the approval of pemetrexed in patients with NSCLC did not report any significant

Manuscript accepted for publication August 18, 2014

aRoyal Adelaide Hospital, Adelaide, South Australia 5000, Australia bepartment of Medical Oncology, Flinders Medical Centre, Bedford Park, Adelaide, South Australia 5042, Australia

${ }^{\mathrm{c} C}$ Corresponding Author: Michael J. Waters, Royal Adelaide Hospital, North Terrace, Adelaide, South Australia 5000, Australia.

Email: michael.waters2@health.sa.gov.au

doi: http://dx.doi.org/10.14740/wjon845w pulmonary toxicity $[3,7]$. However, since 2009, eight reported cases have linked pemetrexed with acute interstitial pneumonitis. As pemetrexed is now a widely used chemotherapeutic agent, it is important to be aware of rare adverse events related to its administration.

\section{Case Report}

A 61-year-old female was diagnosed with stage IV (T2a, N2, M1b) NSCLC in June 2012. Positron emission tomography (PET) scan showed evidence of oligometastatic disease involving the right adrenal gland. She subsequently had a laparoscopic resection of the right adrenal gland in June 2012; pathology results were consistent with a metastatic, poorly differentiated adenocarcinoma of lung origin. She began concurrent chemoradiotherapy in July 2012, with cisplatin and etoposide, and radiotherapy (60 Gy). Treatment was complete by August 2102. Restaging computed tomography (CT) scan showed regression of the primary tumor. There was no evidence of any interstitial lung disease (Fig. 1). In October 2012, 56 days following completion of radiotherapy, maintenance pemetrexed was commenced, $500 \mathrm{mg} / \mathrm{m}^{2}$ every 21 days, with supplemental vitamin B12 and folic acid.

In November 2012, 13 days after the second dose of peme-

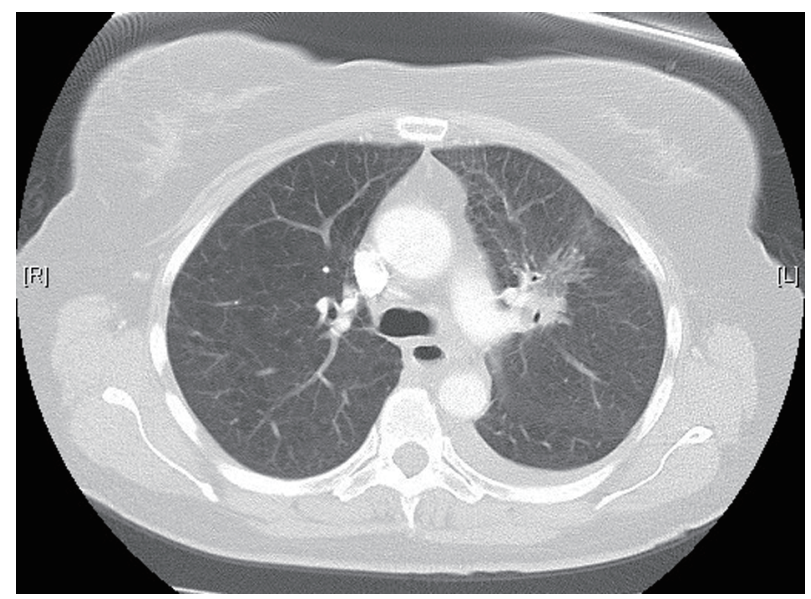

Figure 1. High-resolution lung computed tomography before pemetrexed administration. 


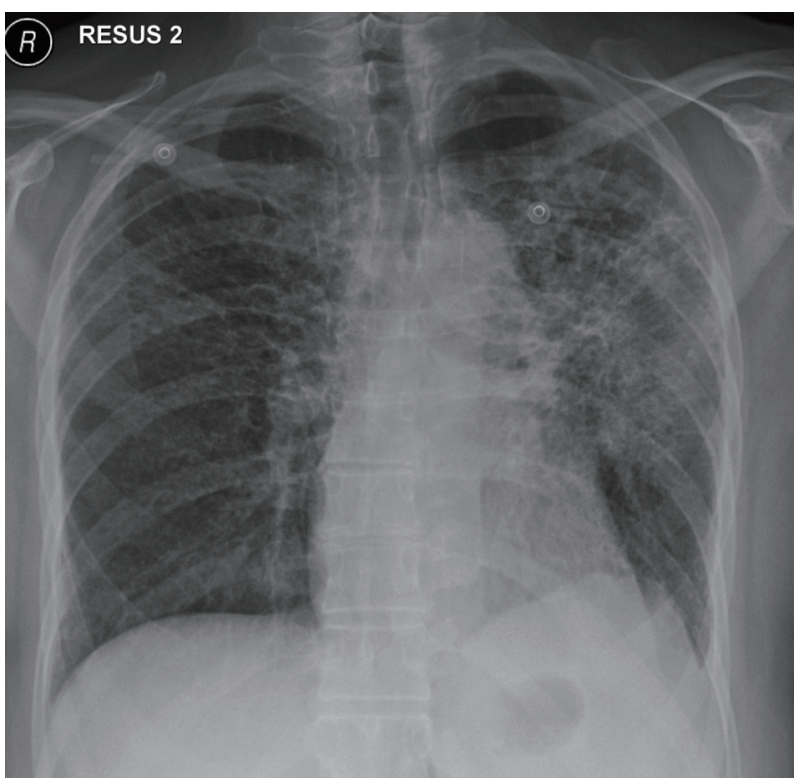

Figure 2. Chest X-ray on initial presentation, showing diffuse bilateral reticulonodular opacities in the upper lobes.

trexed, the patient presented to our tertiary referral center after developing fever, cough, lethargy and dyspnoea at rest. She had no chest pain or pedal edema. On initial examination, the patient was febrile (temperature $38^{\circ} \mathrm{C}$ ) and in visible respiratory distress with a respiratory rate of 30 breaths/min and oxygen saturation $78 \%$ on room air. An arterial blood gas analysis taken on $8 \mathrm{~L} / \mathrm{min}$ of oxygen showed hypoxia with a respiratory alkalosis ( $\mathrm{pH} 7.47, \mathrm{PO}_{2} 73 \mathrm{~mm} \mathrm{Hg}$, and $\left.\mathrm{PCO}_{2} 32 \mathrm{~mm} \mathrm{Hg}\right)$. Chest X-ray showed diffuse reticulonodular opacities in the upper lobes bilaterally (Fig. 2). CT scan revealed widespread interstitial opacity with inter- and intra-lobular septal thickening, and fine nodularity throughout both lung fields (Fig. 3). In some regions the diffuse interstitial opacity gave a ground glass appearance. The radiological changes were diffuse, including areas outside of the previous radiotherapy field. There

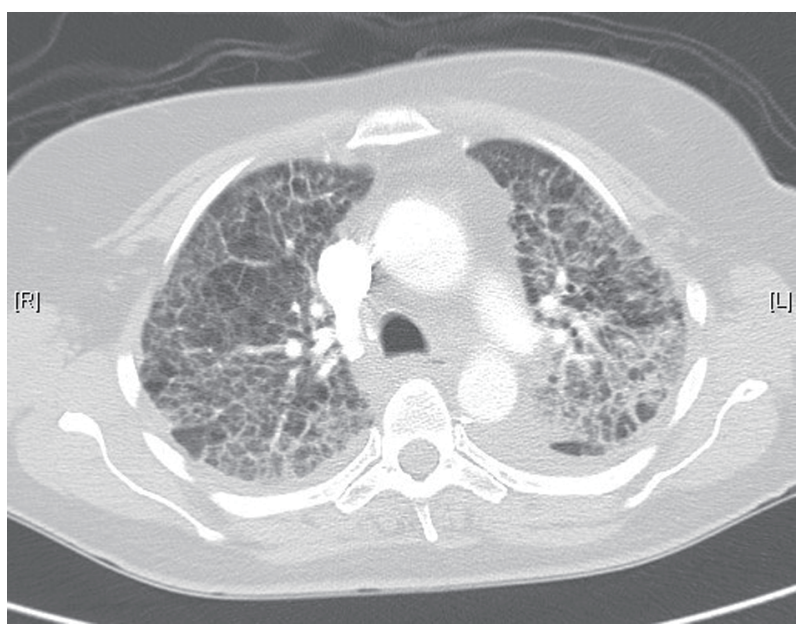

Figure 3. Lung computed tomography during acute illness, showing bilateral diffuse interstitial changes and ground-glass opacities.

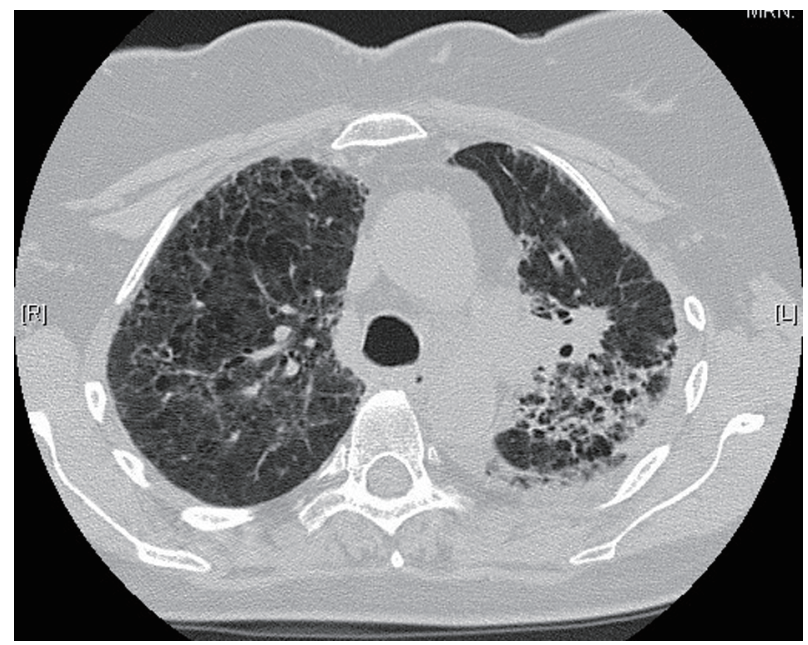

Figure 4. High-resolution lung computed tomography 1 month postillness, showing interval resolution of interstitial changes.

was no evidence of pulmonary embolus. Her white cell count was not elevated $\left(4 \times 10^{9} / \mathrm{L}\right.$; neutrophils $\left.3.5 \times 10^{9} / \mathrm{L}\right)$ and hemoglobin level was $101 \mathrm{~g} / \mathrm{L}$. Tests of renal and liver function were normal. C-reactive protein was $170 \mathrm{mg} / \mathrm{L}$ (normal $<8$ $\mathrm{mg} / \mathrm{L}$ ). She was commenced on broad spectrum intravenous antibiotics and transferred to the intensive care unit (ICU) due to ongoing hypoxia and respiratory distress. In the ICU she was commenced on intravenous dexamethasone and placed on non-invasive ventilation. She improved rapidly over the next 3 - 4 days. Repeated blood cultures and induced sputum did not reveal evidence of a typical or atypical infective cause. Bronchoscopy was not performed as the patient was not fit for the procedure whilst acutely unwell. She improved rapidly with conservative management.

The patient returned home 10 days following hospital admission. She was not rechallenged with pemetrexed. High-resolution CT 1 month following her hospital admission showed interval resolution of the ground-glass attenuation, and complete resolution of the alveolar changes present during acute

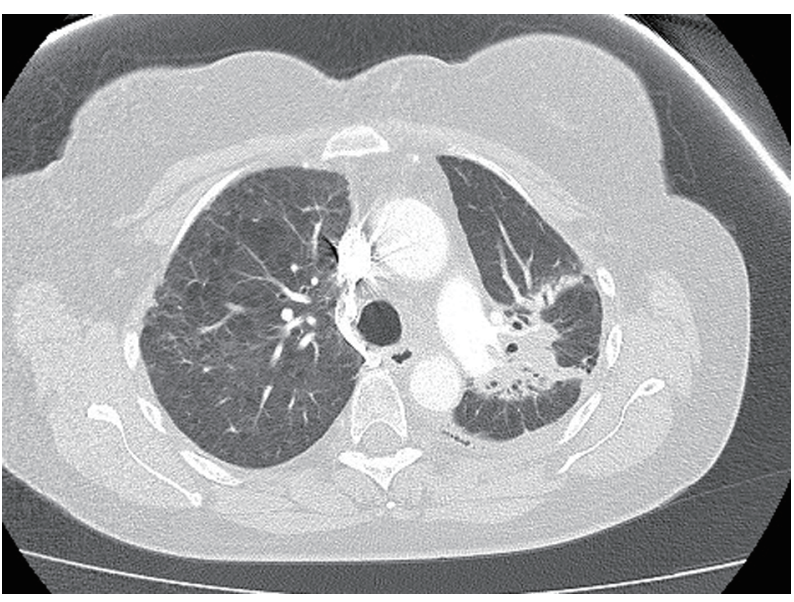

Figure 5. Further resolution on computed tomography, 4 months postillness. 


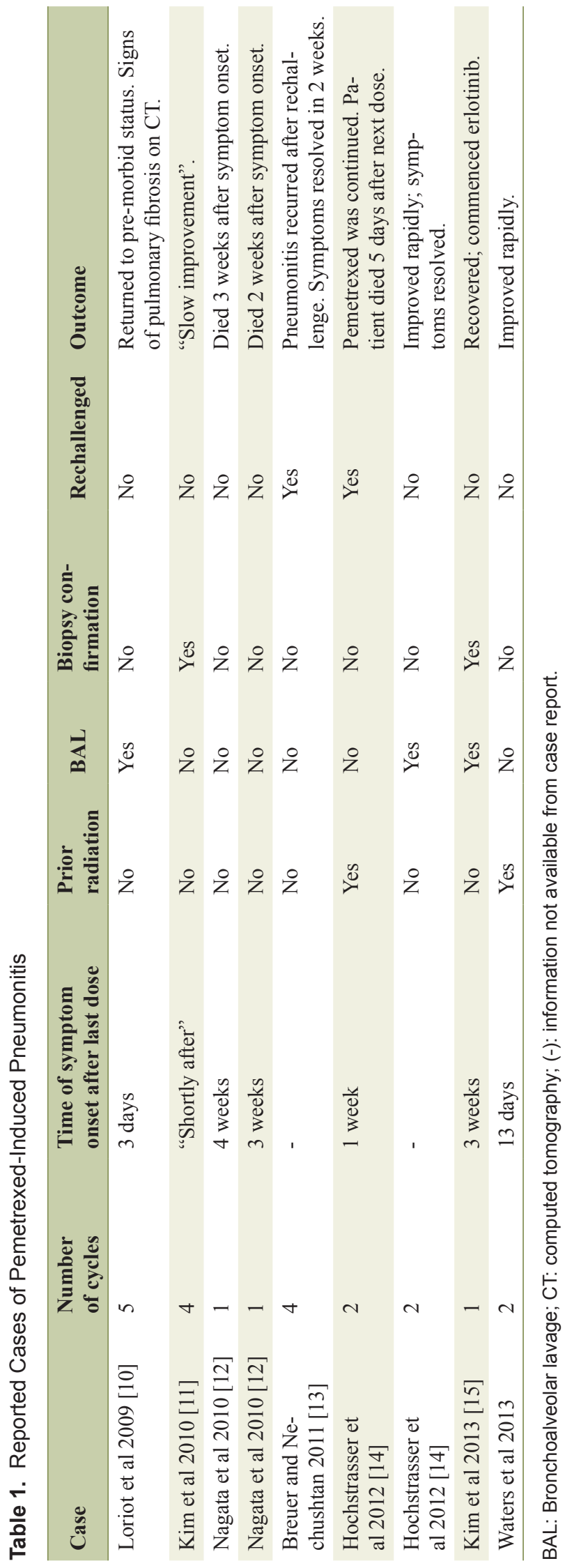

illness (Fig. 4). There was further resolution evident on repeat CT scanning 4 months post-illness (Fig. 5). She is currently on surveillance.

\section{Discussion}

Chemotherapy-induced lung toxicity occurs in less than $10 \%$ of patients on cytotoxic agents; however, it can be severe, rapidly progressive and potentially fatal [8]. Methotrexate, bleomycin, gemcitabine and cyclophosphamide are the best-known causative agents. Interstitial pneumonitis is the most common presentation of chemotherapy-induced lung toxicity [8].

The use of pemetrexed as a chemotherapeutic agent is growing, given recent evidence supporting its use in patients with NSCLC and malignant mesothelioma. Acute lung injury was not reported as a side effect of pemetrexed from the phase III clinical trials leading to its widespread use for NSCLC [3, 7]. Since then, Ohe et al [9] reported eight cases of interstitial pneumonitis in patients treated with pemetrexed, although sufficient clinical data linking the two were lacking. Performing a comprehensive literature review, we identified eight case reports in the English literature linking pemetrexed to acute lung injury [10-15] (Table 1).

There is no definitive diagnostic test for pemetrexedinduced interstitial pneumonitis. Diagnosis remains one of exclusion, based on clinical manifestations, radiographic abnormalities, bronchoalveolar lavage (BAL) analysis, lung histology when available, and resolution of symptoms after drug discontinuation. Bacterial and viral infection should be excluded. Lymphangitis carcinomatous and radiation pneumonitis should also be considered in the differential diagnosis. Definitive diagnosis remains a challenge for clinicians, as clinical and histopathological signs are non-specific. All eight patients from the previously reported case studies (Table 1) presented with acute onset dyspnoea and cough whilst on pemetrexed therapy for NSCLC or advanced mesothelioma. The majority of cases also presented with fever, although an infective source was not isolated in any of the cases.

It is arguable whether all eight reported cases can be conclusively linked to pemetrexed administration. An infective source was actively excluded in all cases, and imaging was consistent with interstitial pneumonitis. None of the eight patients had a previous history of interstitial lung disease. Only one of the eight case studies reported prior radiation therapy, concluding 76 days prior to onset of symptoms [14]. However, only two cases were supported with lung biopsy [11, 15], showing a picture of diffuse alveolar damage, alveolar wall thickening and mononuclear inflammatory cell infiltrate. These patterns are non-specific, seen in infections and other drug-induced lung injury, including that due to methotrexate [16]. BAL was performed in three of the eight cases [10, 14, 15]. This investigation is not specific for drug-induced pneumonitis, but may help to rule out infection and lymphangitic tumor. Lymphocytosis and an increase in the CD4/CD8 ratio has been reported from BAL in patients with methotrexateinduced pneumonitis [17].

In our case, we did not have the benefit of lung biopsy or 
BAL. However, the lack of infective organism isolated, and the strong response to steroids coupled with interval radiological resolution at 1 month, supports a drug-induced mechanism. Radiation-induced pneumonitis is a well-documented side effect of radiotherapy and was considered in our differential diagnosis. It usually conforms to the prior radiation field, although widespread pneumonitis outside the irradiated field has also been reported [18]. Onset is classically 4 - 6 weeks following irradiation [19]. Mean durations from treatment completion to clinical onset of 14.9 days [20] and 21 days [21] respectively have been reported. Our patient completed her course of radiotherapy 13 weeks (90 days) before the onset of pneumonitis, making a direct causal relationship less likely. However, radiation pneumonitis cannot be completely excluded. Radiation-recall pneumonitis, another differential diagnosis, is a poorly understood phenomenon, associated with multiple chemotherapeutic agents $[22,23]$. Clinical onset can occur months to years after radiotherapy, although lung pathology usually conforms to the prior radiation field [24].

Methotrexate is known to cause interstitial pneumonitis [25], with most researchers suggesting a hypersensitivity mechanism resulting in lung injury $[26,27]$. Usual presence of fever, eosinophilia and a mononuclear cell infiltrate of the lungs on biopsy support this mechanism [27]. The mechanism of pemetrexed-induced interstitial pneumonitis may also be a hypersensitivity reaction. CD4/CD8 ratios from BAL in two of the case studies support a hypersensitivity hypothesis [10, 14].

Another possible mechanism of pemetrexed-induced interstitial pneumonitis may be a toxic drug reaction resulting from accumulation within lung tissue, supported by the resolution of most cases after pemetrexed cessation. However, from the eight reported cases in the literature, clinical onset of pneumonitis does not appear to relate to the duration of pemetrexed therapy. The same holds true for cases of methotrexateinduced lung injury, where dose and duration of drug therapy do not correlate with onset or severity of lung injury [16].

From the eight reported cases of pemetrexed-induced pneumonitis, three patients $(38 \%)$ died, with one following re-exposure to pemetrexed. The others $(62 \%)$ showed signs of improvement following initial presentation, some of these with rapid return to pre-morbid function following the cessation of pemetrexed and administration of steroids.

We did not rechallenge our patient with pemetrexed after her initial presentation, and believe it may be unwise to do so. Two of the previously reported cases reintroduced pemetrexed; one case resulted in a fatal outcome [14], and the other had symptom recurrence which then abated on further pemetrexed cessation [13]. Although there is some evidence to suggest the reintroduction of methotrexate after methotrexate-induced lung injury is safe in the majority of cases [16], we believe the risks of rechallenging with pemetrexed outweigh the benefits, given our current knowledge.

\section{Conclusion}

Interstitial pneumonitis appears to be a rare side effect of pemetrexed therapy. Diagnosis should be suspected when there is a temporal association and other causes have been excluded. Treatment is conservative with steroids and temporary ventilatory support may be required. Radiotherapy may predispose patients to this complication; further clinical studies are required. Rechallenging with pemetrexed after the initial presentation is not advised and may have fatal consequences.

\section{Conflict of Interest}

The authors declare they have no conflict of interest in regard to this manuscript. We declare no financial or personal relationships with people or organizations that could inappropriately influence our work.

\section{Sources of Funding}

None.

\section{Author Note}

The study was performed at Flinders Medical Centre and Flinders University School of Medicine, Bedford Park, Adelaide, South Australia 5042.

\section{References}

1. Goldman ID, Zhao R. Molecular, biochemical, and cellular pharmacology of pemetrexed. Semin Oncol. 2002;29(6 Suppl 18):3-17.

2. Shih C, Chen VJ, Gossett LS, Gates SB, MacKellar WC, Habeck LL, Shackelford KA, et al. LY231514, a pyrrolo[2,3-d]pyrimidine-based antifolate that inhibits multiple folate-requiring enzymes. Cancer Res. 1997;57(6):1116-1123.

3. Scagliotti GV, Parikh P, von Pawel J, Biesma B, Vansteenkiste J, Manegold C, Serwatowski P, et al. Phase III study comparing cisplatin plus gemcitabine with cisplatin plus pemetrexed in chemotherapy-naive patients with advanced-stage non-small-cell lung cancer. J Clin Oncol. 2008;26(21):3543-3551.

4. Hanna N, Shepherd FA, Fossella FV, Pereira JR, De Marinis F, von Pawel J, Gatzemeier U, et al. Randomized phase III trial of pemetrexed versus docetaxel in patients with non-small-cell lung cancer previously treated with chemotherapy. J Clin Oncol. 2004;22(9):1589-1597.

5. Ciuleanu T, Brodowicz T, Zielinski C, Kim JH, Krzakowski M, Laack E, Wu YL, et al. Maintenance pemetrexed plus best supportive care versus placebo plus best supportive care for non-small-cell lung cancer: a randomised, double-blind, phase 3 study. Lancet. 2009;374(9699):1432-1440.

6. Vogelzang NJ, Rusthoven JJ, Symanowski J, Denham C, Kaukel E, Ruffie P, Gatzemeier U, et al. Phase III study of pemetrexed in combination with cisplatin versus cisplatin 
alone in patients with malignant pleural mesothelioma. J Clin Oncol. 2003;21(14):2636-2644.

7. Pujol JL, Paul S, Chouaki N, Peterson P, Moore P, Berry DA, Salzberg M. Survival without common toxicity criteria grade $3 / 4$ toxicity for pemetrexed compared with docetaxel in previously treated patients with advanced nonsmall cell lung cancer (NSCLC): a risk-benefit analysis. J Thorac Oncol. 2007;2(5):397-401.

8. Limper AH. Chemotherapy-induced lung disease. Clin Chest Med. 2004;25(1):53-64.

9. Ohe Y, Ichinose Y, Nakagawa K, Tamura T, Kubota K, Yamamoto N, Adachi S, et al. Efficacy and safety of two doses of pemetrexed supplemented with folic acid and vitamin B12 in previously treated patients with non-small cell lung cancer. Clin Cancer Res. 2008;14(13):42064212.

10. Loriot Y, Ferte C, Gomez-Roca C, Moldovan C, Bahleda R, Wislez M, Cadranel J, et al. Pemetrexed-induced pneumonitis: a case report. Clin Lung Cancer. 2009;10(5):364366.

11. Kim HO, Lee SY, Shim JJ, Kang KH, Shin BK. A case of pemetrexed-induced acute lung injury in non-small cell lung cancer. J Thorac Oncol. 2010;5(3):401-402.

12. Nagata K, Kaji R, Tomii K. Fatal pemetrexed-induced lung injury in patients with advanced mesothelioma: a report of two cases. J Thorac Oncol. 2010;5(10):17141715 .

13. Breuer S, Nechushtan H. Pemetrexed-induced lung toxicity: a case report. Clin Oncol (R Coll Radiol). 2012;24(1):76-77.

14. Hochstrasser A, Benz G, Joerger M, Templeton A, Brutsche M, Fruh M. Interstitial pneumonitis after treatment with pemetrexed: a rare event? Chemotherapy. 2012;58(1):84-88.

15. Kim KH, Song SY, Lim KH, Han SS, Kim SH, Cho JH, Park CW, et al. Interstitial Pneumonitis after Treatment with Pemetrexed for Non-small Cell Lung Cancer. Cancer Res Treat. 2013;45(1):74-77.

16. Imokawa S, Colby TV, Leslie KO, Helmers RA. Meth- otrexate pneumonitis: review of the literature and histopathological findings in nine patients. Eur Respir J. 2000;15(2):373-381.

17. Schnabel A, Richter C, Bauerfeind S, Gross WL. Bronchoalveolar lavage cell profile in methotrexate induced pneumonitis. Thorax. 1997;52(4):377-379.

18. Gibson PG, Bryant DH, Morgan GW, Yeates M, Fernandez V, Penny R, Breit SN. Radiation-induced lung injury: a hypersensitivity pneumonitis? Ann Intern Med. 1988;109(4):288-291.

19. Abratt RP, Morgan GW, Silvestri G, Willcox P. Pulmonary complications of radiation therapy. Clin Chest Med. 2004;25(1):167-177.

20. Makimoto T, Tsuchiya S, Hayakawa K, Saitoh R, Mori M. Risk factors for severe radiation pneumonitis in lung cancer. Jpn J Clin Oncol. 1999;29(4):192-197.

21. Monson JM, Stark P, Reilly JJ, Sugarbaker DJ, Strauss GM, Swanson SJ, Decamp MM, et al. Clinical radiation pneumonitis and radiographic changes after thoracic radiation therapy for lung carcinoma. Cancer. 1998;82(5):842-850.

22. Schweitzer VG, Juillard GJ, Bajada CL, Parker RG. Radiation recall dermatitis and pneumonitis in a patient treated with paclitaxel. Cancer. 1995;76(6):1069-1072.

23. Schwarte S, Wagner K, Karstens JH, Bremer M. Radiation recall pneumonitis induced by gemcitabine. Strahlenther Onkol. 2007;183(4):215-217.

24. Ding X, Ji W, Li J, Zhang X, Wang L. Radiation recall pneumonitis induced by chemotherapy after thoracic radiotherapy for lung cancer. Radiat Oncol. 2011;6:24.

25. Grove ML, Hassell AB, Hay EM, Shadforth MF. Adverse reactions to disease-modifying anti-rheumatic drugs in clinical practice. QJM. 2001;94(6):309-319.

26. Cooper JA, Jr., White DA, Matthay RA. Drug-induced pulmonary disease. Part 1: Cytotoxic drugs. Am Rev Respir Dis. 1986;133(2):321-340.

27. Lynch JP, 3rd, McCune WJ. Immunosuppressive and cytotoxic pharmacotherapy for pulmonary disorders. Am J Respir Crit Care Med. 1997;155(2):395-420. 